\title{
Effect of Nucleation and Growth Dynamics on Saturation Magnetization of Chemically Synthesized Fe Nanoparticles
}

\author{
T. Ogawa $^{1 *}$, K. Seto ${ }^{1}$, D. Hasegawa ${ }^{1,2}$, H. T. Yang ${ }^{1,3}$, H. Kura $^{1}$, M. Doi ${ }^{1}$, and M. Takahashi ${ }^{1,4}$ \\ ${ }^{1}$ Department of Electronic Engineering, Graduate School of Engineering, Tohoku University, 6-6-05 Aza-Aoba, Aramaki, Aoba-ku, \\ Sendai 980-8579, Japan \\ ${ }^{2}$ Waseda Institute for Advanced Study, Waseda University, Tokyo 169-8555, Japan \\ ${ }^{3}$ State Key Laboratory of Magnetism, Institute of Physics, Chinese Academy of Chinese, P. O. Box 603, Beijing 100190, China \\ ${ }^{4}$ Center for Nanobioengineering and Spintronics, Chungnam National University, Daejeon 305-764, Korea
}

(Received 19 July 2011, Received in final form 22 August 2011, Accepted 25 August 2011)

\begin{abstract}
In order to obtain mono-dispersed Fe NPs with high saturation magnetization, quantitative analysis method to investigate the growth dynamics of the Fe NPs synthesized by a conventional thermal decomposition method has been developed. As a result, fast nucleation process promotes formation of $\sim \mathbf{4} \mathbf{n m}$ of initial nucleus with a non-equilibrium phase, resulting in low saturation magnetization. And slow particle growth with atomic-scaled surface precipitation mode $\left(<100\right.$ atoms $\left./\left(\mathrm{min} \cdot \mathrm{nm}^{2}\right)\right)$ can form the growth layer on the surface of initial nucleus with high saturation magnetization $\left(\sim 190 \mathrm{emu} / \mathrm{g}_{\mathrm{Fe}}\right)$ as an equilibrium a phase of Fe. Therefore, higher stabilization of small initial nucleus generated just after the injection of $\mathrm{Fe}(\mathrm{CO})_{5}$ should be one of the key issues to achieve much higher $M_{\mathrm{s}}$ of Fe NPs.
\end{abstract}

Keywords : Fe nanoparticles, chemical synthesis, formation dynamics, saturation magnetization

\section{Introduction}

Nano-sized ferromagnetic nanoparticle (NP) with single magnetic domain shows a superparamagnetic behavior due to thermal fluctuation of its magnetic moment, and the NP assembly can be expected as a new soft material with three dimensionally isotropic properties and no loss for possible application to high frequency devices in $\mathrm{GHz}$ range [1,2]. In order to obtain a high permeability, high saturation magnetization $\left(M_{\mathrm{S}}\right)$ of the NP is required, and pure $\alpha$ phase of $\mathrm{Fe}$ is one of the attractive candidates. However, $20-30 \%$ of smaller values of the $M \mathrm{~s}$ than that of bulk $\left(220 \mathrm{emu} / \mathrm{g}_{\mathrm{Fe}}\right)$ have been obtained for the chemically synthesized $\mathrm{Fe} \mathrm{NPs}$ using a $\mathrm{Fe}(\mathrm{CO})_{5}$ as precursor in spite of minimal oxidation during the synthesis [3,4]. Thus, it is necessary to clarify not only the phase of the individual NP but also the relationship between growth process of the phase and $M \mathrm{~s}$.

In this study, firstly, quantitative analysis method of the growth process of the chemically synthesized Fe NPs is introduced especially for numbers of precursor $\mathrm{Fe}(\mathrm{CO})_{5}$,

*Corresponding author: Tel: +81-22-795-7134

Fax:+81-22-263-9402, e-mail: tomoyuki@ecei.tohoku.ac.jp
$\mathrm{Fe}$ atoms consisting of NPs, dissolving $\mathrm{Fe}$ atoms and $\mathrm{Fe}$ NPs as a function of total number of injected Fe atoms and reaction time. And, then, dependence of the NP size with time evolution during the synthesis on $M \mathrm{~s}$ will be discussed, combining with the growth process of the $\mathrm{Fe}$ NPs.

\section{Experimental and Analysis Procedures}

Fe NPs were synthesized by our developed thermal decomposition method [3] using an iron carbonyl $\mathrm{Fe}(\mathrm{CO})_{5}$, whose total number of injected $\mathrm{Fe}$ atoms (hereafter, denoted as $n_{0}$ ) was systematically changed from $0.61 \times$ $10^{21}(1 \mathrm{mmol})$ to $4.30 \times 10^{21}(10 \mathrm{mmol})$, treated in a glove box under $\mathrm{Ar}$ atmosphere with $0.1 \mathrm{ppm}-1 \mathrm{ppm}$ of $\mathrm{O}_{2}$ and $\mathrm{H}_{2} \mathrm{O}$ [3]. 180 deg $\mathrm{C}$ of refluxing temperature was fixed and refluxing time was changed from $1 \mathrm{~min}$. to $60 \mathrm{~min}$. Residual amount of $\mathrm{Fe}(\mathrm{CO})_{5}$, i.e., number of precursor $\mathrm{Fe}(\mathrm{CO})_{5}$ in the reaction solution $\left(n_{\mathrm{m}}\right)$ was quantitatively evaluated by an infra-red (IR) spectra [5]. The Fe NPs covered with surfactant were re-dispersed into kerosene matrix solution after washing by an appropriate amount of acetone. The NP size and crystalline structure were characterized by the transmission electron microscopy 


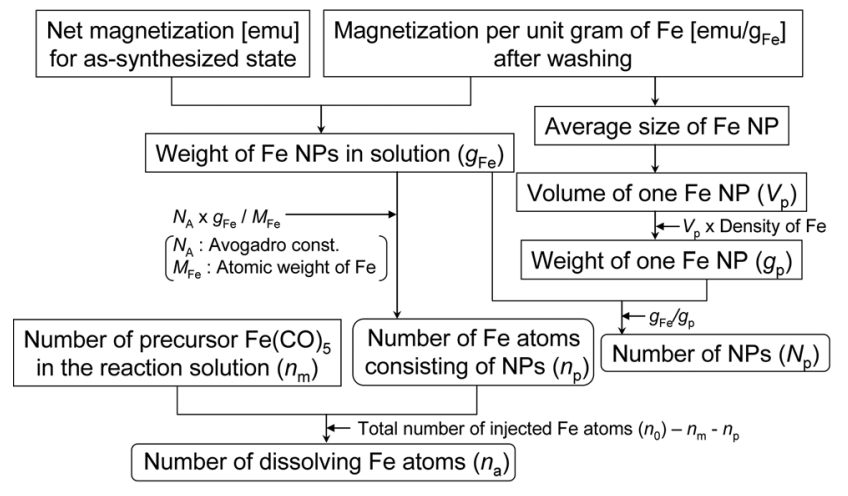

Fig. 1. Quantitative analysis flow chart for evaluating $n_{\mathrm{p}}, n_{\mathrm{a}}$ and $N_{\mathrm{p}}$.

(TEM) and electron diffraction (ED). The saturation magnetization at $5 \mathrm{~K}$ of the Fe NPs encapsulated in a quartz tube with epoxy resin cap were measured by a superconducting quantum interference device (SQUID) and with X-ray Fluorescence (XRF) analysis which provides the amount of $\mathrm{Fe}$ in the disperse solution [3]. Fig. 1 shows a quantitative analysis flow chart for evaluating numbers of Fe atoms consisting of NPs $\left(n_{\mathrm{p}}\right)$, dissolving Fe atoms $\left(n_{\mathrm{a}}\right)$ and Fe NPs $\left(N_{\mathrm{p}}\right)$. The as-synthesized Fe NPs solution includes not only Fe NPs but also residual precursor (paramagnetism) and dissolving Fe atoms (paramagnetism), and on the other hand, only Fe NPs are included for the Fe NPs solution after washing. $N_{\mathrm{A}}, M_{\mathrm{Fe}}$ and density of $\mathrm{Fe}$ are the Avogadro constant $\left(6.022 \times 10^{23}\right.$ $\mathrm{mol}^{-1}$ ), atomic weight of $\mathrm{Fe}$ (55.8) and density of bulk $\left(7.86 \mathrm{~g} / \mathrm{cm}^{3}\right)$, respectively. This analysis was applied to the Fe NPs solution synthesized under various $n_{0}$ and refluxing times.

\section{Results and Discussions}

With increasing the refluxing time, $n_{\mathrm{m}}$ monotonously decreases from $n_{0}$ to zero and, on the other hand, $n_{\mathrm{p}}$ increases from zero to almost $n_{0}$. These behaviors were independent of $n_{0}$. The resultant of $n_{\mathrm{a}}$, expressed as $n_{\mathrm{a}}=$ $n_{0}-n_{\mathrm{m}}-n_{\mathrm{p}}$, monotonously decreased with increasing the refluxing time as shown in Fig. 2. Based on the LaMer model [6], $n_{\mathrm{a}}$ should take a maximum at a certain reaction time, around which the nucleation process from the dissolving Fe atoms was brought about and over which the particle growth process from the initial nuclei was brought about, resulting in decrease in $n_{\mathrm{a}}$ with increasing refluxing time. Thus, the whole obtained result in Fig. 2 reflects the particle growth process within the present investigated refluxing time range from $1 \mathrm{~min}$. to $60 \mathrm{~min}$ and also suggests that the fast nucleation process may be appeared less than $1 \mathrm{~min}$. Furthermore, the particle size increases

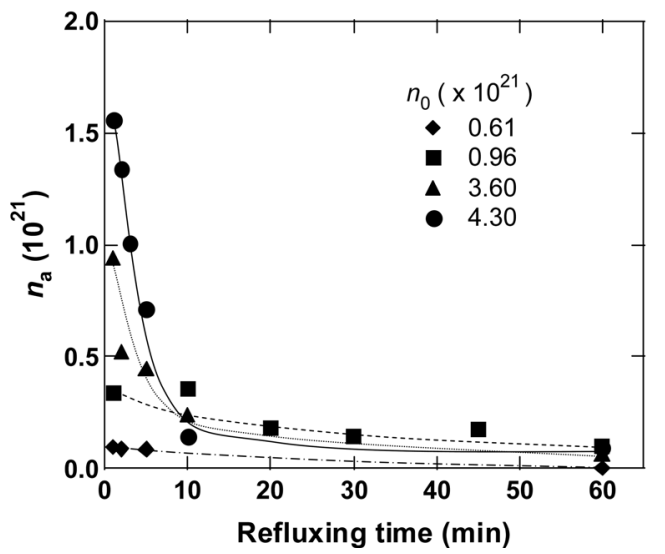

Fig. 2. Refluxing time dependence of $n_{\mathrm{a}}$ for various $n_{0}$.

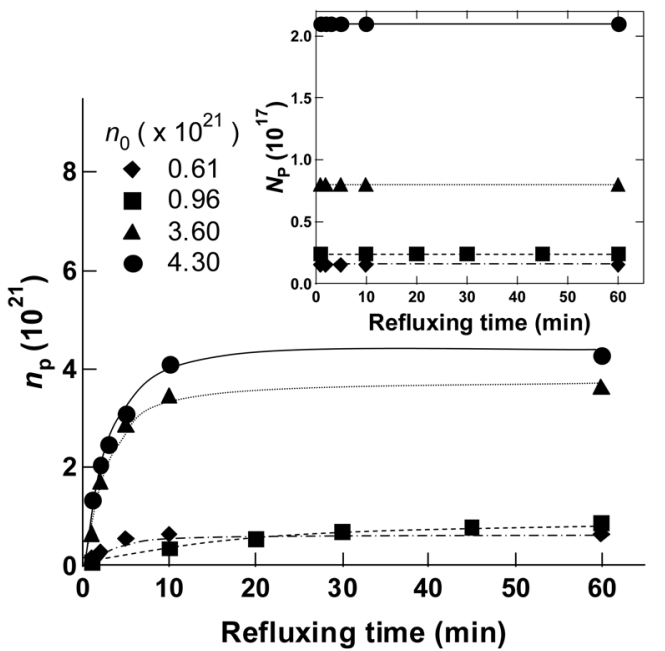

Fig. 3. Refluxing time dependence of $n_{\mathrm{p}}$ and $N_{\mathrm{p}}$ (the inset) for various $n_{0}$.

from 4-6 $\mathrm{nm}$ to $8-10 \mathrm{~nm}$ with increasing the refluxing time from $1 \mathrm{~min}$. to $60 \mathrm{~min}$. This corresponds to increasing behavior of $n_{\mathrm{p}}$ as shown in Fig. 3 although $N_{\mathrm{p}}$ is, interestingly, unchanged within the same refluxing time range shown in the inset in Fig. 3. This result strongly indicates that surface precipitation of $\mathrm{Fe}$ atoms with atomic scale is dominant in the particle growth process rather than co-agglomeration of NPs with nano-sized scale.

We will here define a particle growth rate, expressed as $d\left(n_{\mathrm{p}} / N_{\mathrm{p}}\right) / d t / S_{\mathrm{p}}$, as a number of $\mathrm{Fe}$ atoms which precipitate on particle surface per unit surface area and unit time. This value has an increasing tendency from 0.01 atoms/ $\left(\min \cdot \mathrm{nm}^{2}\right)$ to 87 atoms $/\left(\min \cdot \mathrm{nm}^{2}\right)$ with increasing $n_{\mathrm{a}}$. Comparing the values with those of conventional dry processes for preparing thin film samples, 25,000 atoms/ $\left(\min \cdot \mathrm{nm}^{2}\right)(5 \mathrm{~nm} / \mathrm{sec}$ in thickness) for a sputtering process and 25 atoms $/\left(\mathrm{min} \cdot \mathrm{nm}^{2}\right)(0.005 \mathrm{~nm} / \mathrm{sec})$ for vapor deposition process are usually applied. And the slow vapor 
deposition could realize a thermally equilibrium phase of materials. Thus, the growth rate less than 100 atoms/ $\left(\min \cdot \mathrm{nm}^{2}\right)$ in chemically synthesized Fe NPs can promote a formation of thermally equilibrium phase as a growth layer on the surface of the initial nucleus of the Fe NPs. Next, the size estimated from a simple extrapolation of the particle growth rate at $1 \mathrm{~min}$. to $0 \mathrm{~min}$. of the refluxing time and the particle size at $1 \mathrm{~min}$. may provide lower and upper limits of the size of initial nucleus, respectively. $3.8 \mathrm{~nm}$ in average, $1.4 \mathrm{~nm}$ in minimum and $6.5 \mathrm{~nm}$ at maximum are obtained as the size of initial nucleus for various $n_{0}$. Assuming that the nucleation process is brought about through precipitation of $\mathrm{Fe}$ atoms on surface of one $\mathrm{Fe}$ atom, over 140,000 atoms $/\left(\mathrm{min} \cdot \mathrm{nm}^{2}\right)$ is obtained as a nucleation rate. As a result, fast nucleation rate may promote a formation of non-equilibrium phase. From a previous theoretical literature [7], the size of nuclei is reported to be around $1 \mathrm{~nm}$, which is much small than our experimental result of $3.8 \mathrm{~nm}$ in average. This difference may be attributed to the contribution of fast nucleation process in the most initial stage just after the injection of $\mathrm{Fe}(\mathrm{CO})_{5}$ into the reaction solution. Therefore, fast nucleation process and slow particle growth process could have a possibility to be coexistent of non-equilibrium and equilibrium phases, and have different saturation magnetizations between the initial nucleus and the growth layer covering the nucleus.

In the inset in Fig. 4 shows particle size dependence of $M_{\mathrm{s}}$, for Fe NPs synthesized under various $n_{0}$. The $M_{\mathrm{s}}$ decreases from $\sim 170 \mathrm{emu} / \mathrm{g}_{\mathrm{Fe}}$ to $\sim 100 \mathrm{emu} / \mathrm{g}_{\mathrm{Fe}}$ with decreasing the size, which is independent of $n_{0}$. And in order to separately characterize $M_{\mathrm{s}}$ of the growth layer and initial nucleus, Fig. 4 shows re-plots of $M_{\mathrm{s}} V_{\mathrm{p}}$ v.s. $V_{\mathrm{p}}$ from the data of the inset in Fig. 4 [8,9], where $V_{\mathrm{p}}$ is the volume of Fe NPs assuming the sphere shape of Fe NP. All of the plots have a linear relationship, where $\sim 190 \mathrm{emu} / \mathrm{g}_{\mathrm{Fe}}$ from the slopes and $3.8 \mathrm{~nm}-4.8 \mathrm{~nm}$ from the intercepts on the horizontal axis are obtained. This suggests low $M_{\mathrm{s}}(\sim 0$ $\mathrm{emu} / \mathrm{g}_{\mathrm{Fe}}$ ) core with $3.8 \mathrm{~nm}-4.8 \mathrm{~nm}$ covered by high $M_{\mathrm{s}}$ shell $\left(190 \mathrm{emu} / \mathrm{g}_{\mathrm{Fe}}\right)$ structure, which corresponds to initial nucleus and growth layer, respectively. The estimated core size roughly agrees with $1.4 \mathrm{~nm}-6.5 \mathrm{~nm}$ of the initial nucleus size discussed in the previous paragraph. Thus, magnetically inhomogeneous nanostructure was realized even in one Fe NP, resulting in decrease in the saturation magnetization of one Fe NP as a net value $(\sim 170 \mathrm{emu} /$ $\mathrm{g}_{\mathrm{Fe}}$ ). Indeed, Fig. 5 shows typical TEM images and their ED patterns for Fe NPs synthesized under $n_{0}=0.96 \times$ $10^{21}$ for (a) $1 \mathrm{~min}$. and (b) $60 \mathrm{~min}$., where the particle sizes are $4.2 \mathrm{~nm}$ and $9.8 \mathrm{~nm}$, respectively. From ED patterns, a phase of $\mathrm{Fe}$ is observed for $9.8 \mathrm{~nm}$ and, on the

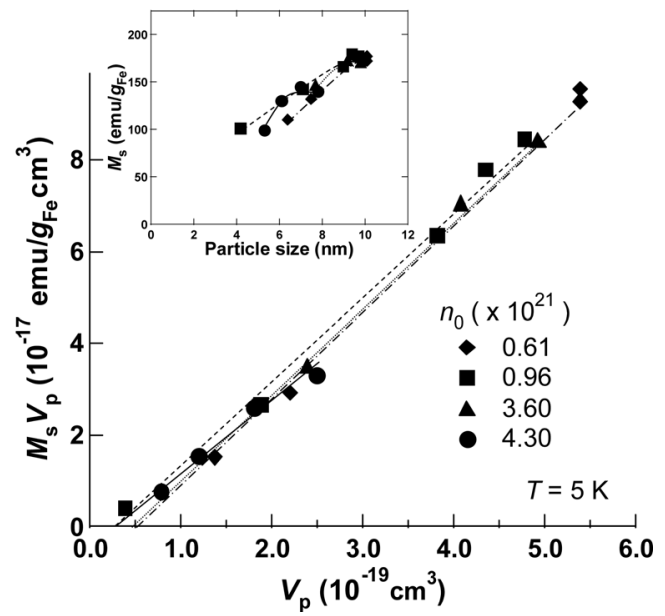

Fig. 4. $M_{\mathrm{s}} V_{\mathrm{p}}$ v.s. $V_{\mathrm{p}}$ plots for various $n_{0}$ and their fitted straight line. The inset shows particle size dependence of saturation magnetization at $5 \mathrm{~K}$ for Fe NPs synthesized under various $n_{0}$.

other hand, almost halo pattern for $4.2 \mathrm{~nm}$. Furthermore, from a fitting of a Mössbauer spectrum for $9.8 \mathrm{~nm}$ at R.T., broadened one absorption peak near zero velocity consisting of two components with small Isomer shift $(0.06 \mathrm{~mm} / \mathrm{sec})$ and relatively larger one $(0.99 \mathrm{~mm} / \mathrm{sec})$ was observed. This indicates that the synthesized Fe NPs show a superparamagnetic state and also indicates that two different Fe states with zero and non-zero valencies are coexistent. And these two different Fe states will support our analysis and interpretation of $M_{\mathrm{s}}$ data discussed in Fig. 4. Therefore, the growth layer covering the initial nucleus of the Fe NPs is formed by pure metallic a phase of Fe which has high $M_{\mathrm{s}}\left(\sim 190 \mathrm{emu} / \mathrm{g}_{\mathrm{Fe}}\right)$ and the initial nucleus by an unknown phase related to $\mathrm{Fe}$ atoms with non-zero valency, which may originate from hydrogen, carbon or nitrogen related impurities provided into the initial nucleus through fast nucleation process, resulting in low $M_{\mathrm{s}}\left(\sim 0 \mathrm{emu} / \mathrm{g}_{\mathrm{Fe}}\right)$ of the nucleus. In order to synthesize Fe NPs with much higher $M_{\mathrm{s}}$, decrease in size of the initial nucleus should be needed by higher stabilization of small initial nucleus and/or seeding with sub-nano scaled

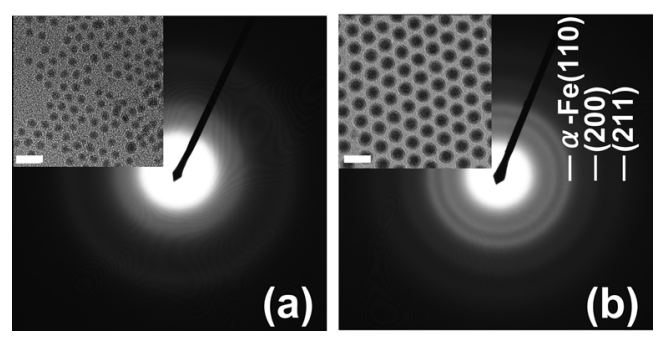

Fig. 5. Typical TEM images and their ED patterns for Fe NPs synthesized under $n_{0}=0.96 \times 10^{21}$ for (a) $1 \mathrm{~min}$. and (b) 60 min. White scale bar in TEM images denotes $20 \mathrm{~nm}$. 
cluster. In our recent study [10], by applying newly developed a $\mathrm{Fe}(\mathrm{CO})_{\mathrm{x}}$-Oleylamine reacted precursor, higher $M_{\mathrm{S}}$ values of $192 \mathrm{emu} / \mathrm{g}_{\mathrm{Fe}}$ could be obtained for $10.0 \mathrm{~nm}$ in diameter and $160 \mathrm{emu} / \mathrm{g}_{\mathrm{Fe}}$ even for $2.3 \mathrm{~nm}$ due to lesser amounts of impurities. In this synthesis, highly stabilized small initial nucleus may also be possibly achieved because $2.3 \mathrm{~nm}$ of the particle size is much smaller than the present smallest size $(4.2 \mathrm{~nm}-6.2 \mathrm{~nm})$ of the Fe NPs synthesized using $\mathrm{Fe}(\mathrm{CO})_{5}$ even after 1 min. of refluxing time.

\section{Conclusion}

In order to obtain mono-dispersed Fe NPs with high saturation magnetization, quantitative analysis method to investigate the growth dynamics of the Fe NPs synthesized by thermal decomposition method has been developed. As a result, fast nucleation process promotes formation of $\sim 4 \mathrm{~nm}$ of initial nucleus with a non-equilibrium phase, resulting in low $M_{\mathrm{s}}$. And slow particle growth with atomicscaled surface precipitation mode $\left(<100\right.$ atoms $\left./\left(\min \cdot \mathrm{nm}^{2}\right)\right)$ can form the growth layer on the surface of initial nucleus with high saturation magnetization $\left(\sim 190 \mathrm{emu} / \mathrm{g}_{\mathrm{Fe}}\right)$ as an equilibrium a phase of $\mathrm{Fe}$. Therefore, higher stabilization of small initial nucleus generated just after the injection of $\mathrm{Fe}(\mathrm{CO})_{5}$ should be one of the key issues to achieve much higher $M_{\mathrm{s}}$ of Fe NPs.

\section{Acknowledgements}

This work is partially supported by Program for Improvement of Research Environment for Young Researchers from MEXT of Japan and by WCU (World Class University) program through the National Research Foundation of Korea funded by the Ministry of Education, Science and Technology (R32-20026).

\section{References}

[1] D. Hasegawa, H. Yang, T. Ogawa, and M. Takahashi, J. Magn. Magn. Mater. 321, 746 (2009).

[2] D. Hasegawa, T. Ogawa, M. Yamaguchi, and M. Takahashi, J. Magn. Soc. Jpn. 30, 528 (2006).

[3] H. Matsuura, K. Seto, H. Yang, K. Kawano, M. Takahashi, and T. Ogawa, IEEE Trans. Magn. 44, 2804 (2008).

[4] H. Yang, F. Ito, D. Hasegawa, T. Ogawa, and M. Takahashi, J. Appl. Phys. 101, 09J112 (2007).

[5] T. Ogawa, K. Seto, D. Hasegawa, H. T. Yang, and M. Takahashi, J. Magn. Soc. Jpn. 33, 247 (2009).

[6] V. K. LaMer and R. H. Dinegar, J. Am. Chem. Soc. 72, 4847 (1950).

[7] V. Ruth, J. P. Hirth, and G. M. Pound, J. Chem. Phys. 88, 7079 (1988).

[8] N. Itagaki, S. Saito, and M. Takahashi, IEEE Trans. Magn. 41, 3187 (2005).

[9] S. Saito, D. Hasegawa, F. Hoshi, David D. Djayaprawira, and M. Takahashi, Appl. Phys. Lett. 80, 811 (2002).

[10] H. Kura, M. Takahashi, and T. Ogawa, J. Phys. Chem. C 114, 5835 (2010). 